\title{
Scanning Electron Microscopic Study of the Tongue in the Peregrine Falcon and Common Kestrel
}

\author{
By \\ Shoichi EMURA ${ }^{1}$, Toshihiko OKUMURA ${ }^{2}$ and Huayue CHEN ${ }^{3}$ \\ ${ }^{1}$ Nursing Course, Gifu University School of Medicine, Gifu 501-1193, Japan \\ ${ }^{2}$ Laboratory of Technology, Gifu University School of Medicine, Gifu 501-1194, Japan \\ ${ }^{3}$ Department of Anatomy, Gifu University Graduate School of Medicine, Gifu 501-1194, Japan \\ - Received for Publication, February 7, 2008-

\begin{abstract}
Summary: The dorsal lingual surfaces of an adult peregrine falcon (Falco peregrinus) and common kestrel (Falco tinnunculus) were examined by scanning electron microscopy. The length of the tongue in the peregrine falcon was about 2.5 $\mathrm{cm}$. The length of the tongue in the common kestrel was about $1.5 \mathrm{~cm}$. The tips of the tongues of the peregrine falcon and common kestrel were bifid. Three parts were distinguished in the tongues of the peregrine falcon and common kestrel: the apex, the body and the root of the tongue. The region of the openings of the lingual glands between the lingual apex and lingual root was very wide area in each bird. There were carpet-shaped epithelium in the lingual apex in each bird. The many openings of the lingual glands existed in the lingual body and lingual root in each bird. The morphological characteristics of the tongues in the peregrine falcon and common kestrel were similar to each other.
\end{abstract}

Key Words: Peregrine falcon, Common kestrel, Lingual papillae, SEM

The studies on the structure of the tongue in birds have been conducted on a small number of species, i.e. chickens, parrot, geese, eagle and cormorant (Iwasaki and Kobayashi, 1986; Homberger and Brush, 1986; Iwasaki et al., 1997; Jackowiak and Godynicki, 2005; Jackowiak et al., 2006). The results of morphological studies conducted so far indicate a close correlation of the shape of the tongue with the method of food intake and the type of food, and habitat.

However, no scanning electron microscopic (SEM) study of the tongue of the owl has been carried out. The purpose of this study is, therefore, to examine threedimensionally the dorsal lingual surface of the owl, in order to compare the results with those previous reports in other birds.

\section{Materials and Methods}

The tongues of an adult peregrine falcon (Falco peregrinus) and common kestrel (Falco tinnunculus) of the family Falconidae were used in this study. The tongues were fixed in $10 \%$ formalin. Small blocks containing papillae were cut with a razor blade, post-fixed with $1 \%$ osmium tetroxide for $1 \mathrm{~h}$. Thereafter, the specimens were dehydrated through graded series of acetone and criticalpoint-dried. To show the three-dimensional connective tissue structure of the lamina propria of the mucosa, some of the samples were washed in distilled water after fixation and macerated in $3.5 \mathrm{~N} \mathrm{HCl}$ at room temperature for 6 days. After maceration tissues were washed in the distilled water and post-fixed in $1 \%$ osmium tetroxide for $1 \mathrm{~h}$, and dehydrated in a series of acetone and criticalpoint-dried. All specimens were sputtered with Pt-Pd before being examined under SEM (Hitachi S-3500N, Tokyo, Japan) at an accelerating voltage of $15 \mathrm{kV}$.

\section{Results}

The tongue of the adult peregrine falcon is about 2.5 $\mathrm{cm}$ long. The tongue of the adult common kestrel is about $1.5 \mathrm{~cm}$ long. The tips of the tongues of the peregrine falcon and common kestrel were bifid (Fig. 1 and 3). Three parts are distinguished in the dorsal surface of the tongue: the apex, the body and the root of the tongue in each bird (Fig. 1 and 3). The region of the openings of the lingual glands between the lingual apex and lingual root are very wide area (Fig. 1, 2c, 2d, 3, 4c and 4d). Many conical papillae of the lingual body are inclined toward the posterior of the tongue on the posterior end (Figs. 1, 2e, 2f, 3, $4 \mathrm{e}$ and $4 \mathrm{f}$ ). At low magnification of scanning electron microscopy, many processes are observed densely distributed over the entire lingual apex of the dorsal surface (Fig. 


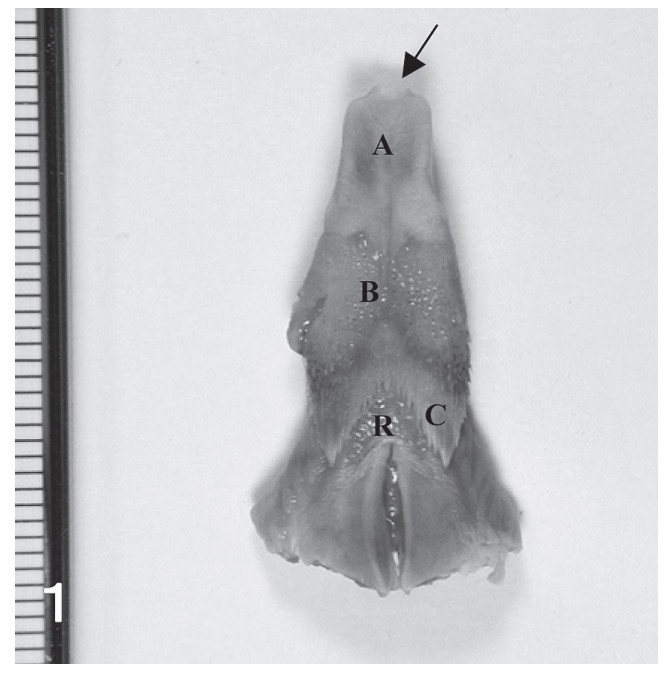

Fig. 1. Macrograph of a peregrine falcon tongue. Three parts are distinguished in the tongue: lingual apex (A), lingual body (B) and lingual root (R). Note the tip of the tongue (arrow) separated into two parts. $\mathrm{C}=$ conical papillae. Scale: $1 \mathrm{~mm}$.
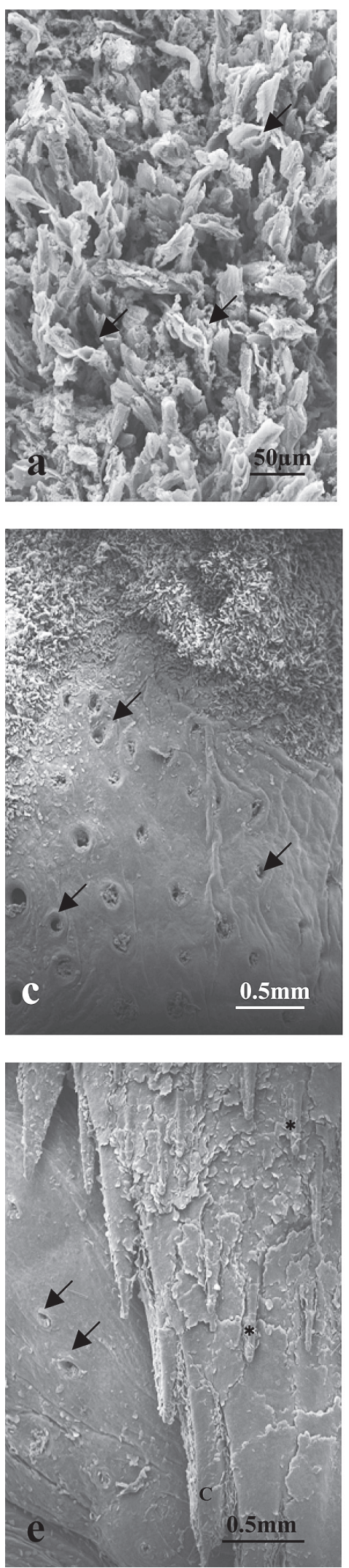
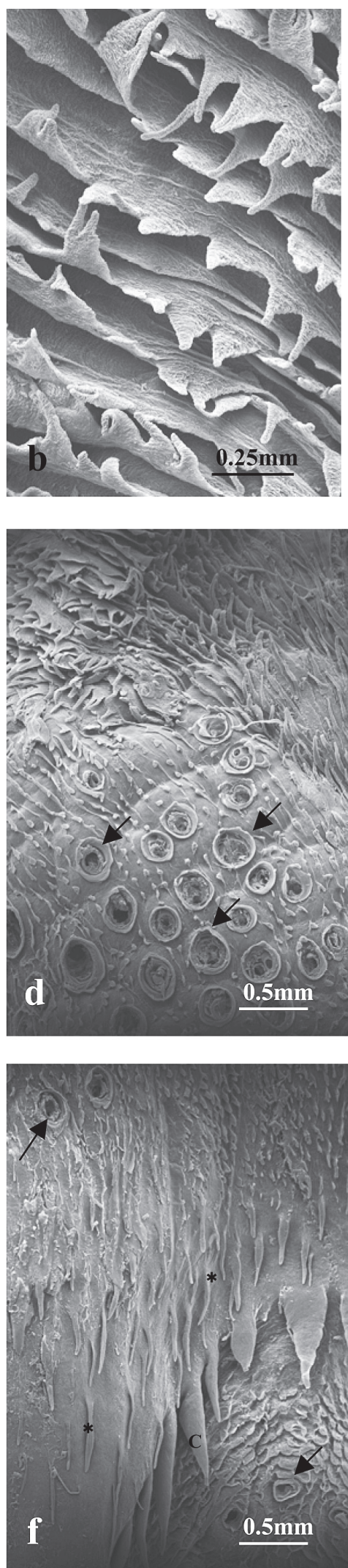

Fig. 2. Scanning electron micrograph of the lingual surface of the peregrine falcon. (a) There are carpetshaped epithelium in the lingual apex. Arrows = tubule-shaped epithelium. (b) The connective tissue cores of the epithelium of the lingual apex show saw-shaped protrusions in the peregrine falcon. (c, d) The many openings of the lingual glands (arrows) exist in the lingual body. (e, f) Many conical papillae of the lingual body are inclined toward the posterior of the tongue on the posterior end. Arrows $=$ openings of the lingual glands. $(*)=$ small conical papillae or the connective tissue cores. $\mathrm{C}=$ large conical papilla or the connective tissue core. 


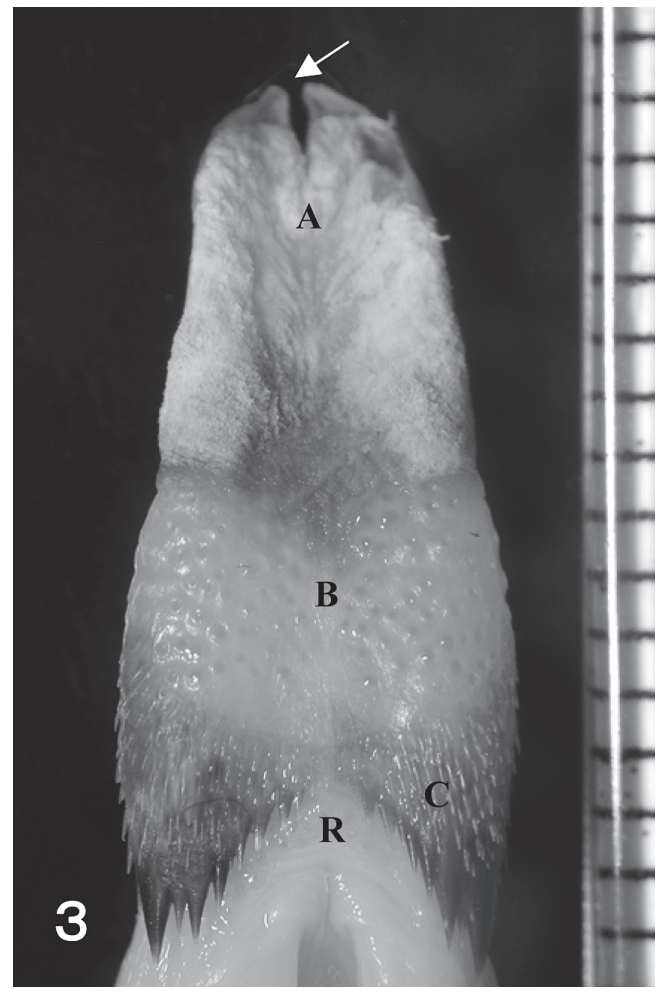

Fig. 3. Macrograph of a common kestrel tongue. Three parts are distinguished in the tongue: lingual apex (A), lingual body (B) and lingual root (R). Note the tip of the tongue (arrow) separated into two parts. $\mathrm{C}=$ conical papillae. Scale: $1 \mathrm{~mm}$.
Fig. 3. Scanning electron micrograph of the lingual surface of the common kestrel. (a) There are carpet-shaped epithelium in the lingual apex. (b) The connective tissue cores of the epithelium of the lingual apex show thread-shaped protrusions in the common kestrel. (c, d) The many openings of the lingual glands (arrows) exist in the lingual body. (e, f) Many conical papillae of the lingual body are inclined toward the posterior of the tongue on the posterior end. Arrows = openings of the lingual glands. $(*)=$ small conical papillae or the connective tissue cores. $\mathrm{C}=$ large conical papilla or the connective tissue core.
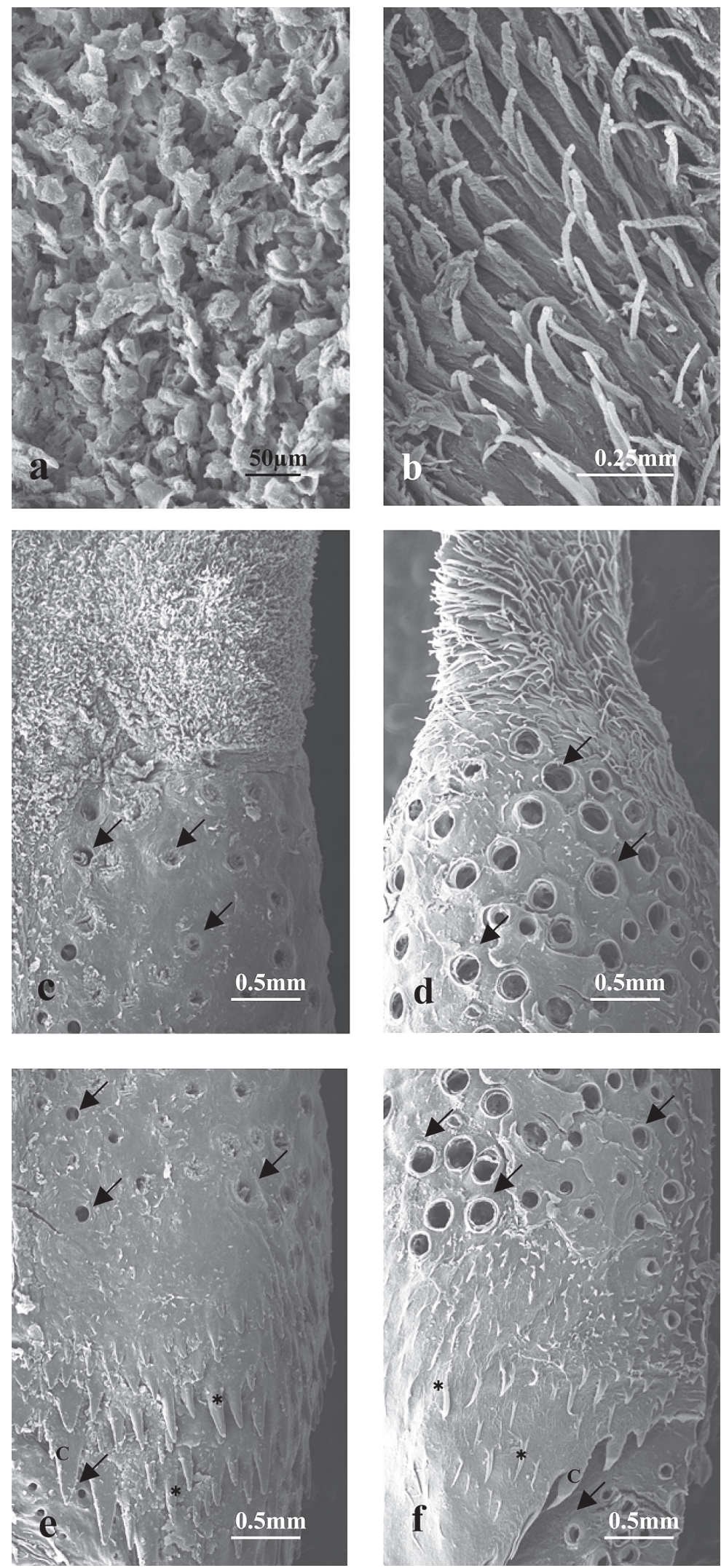
$2 \mathrm{a}$ and $4 \mathrm{a})$. Each epithelium presents the carpet-shaped aspect (Fig. 2a and 4a). The connective tissue cores of the epithelium of the lingual apex show saw-shaped protrusions in the peregrine falcon (Fig. 2b). The connective tissue cores of the epithelium of the lingual apex show thread-shaped protrusions in the common kestrel (Fig. $4 \mathrm{~b})$. The many openings of the lingual glands exist in the lingual body and lingual root (Figs. 2c, 2d, 2e, 2f, 4c, 4d, $4 \mathrm{e}$ and $4 \mathrm{f}$ ). Around the glandular openings the connective tissue ridges form circular sheaths (Fig. 2d, 2f, 4d and 4f).

\section{Discussion}

All birds are adapted to their different environments with respect to food sources. Reflecting their different lifestyles, birds have different feeding habits, with corresponding differences in the structures of their bills and tongues.

In the present study, the tips of the tongues were bifid. Similar structures were showed on the northern fur seal (Emura et al., 2001) and beaver (Shindo et al., 2006). However, there has been no report of the tongues in the birds.

Iwasaki and Kobayashi (1986) reported that the many processes were observed densely distributed over the entire anterior $2 / 3$ of the dorsal surface in the chicken tongue at low magnification of scanning electron microscopy. This result was the same as those of the lingual apices in the peregrine falcon and common kestrel examined under a scanning electron microscope. There were carpet-shaped epithelium in the lingual apex in each bird. However, that of the chicken presented a flattened and slightly twisted aspect (Iwasaki and Kobayashi, 1986). The connective tissue cores of the epithelium of the lingual apex showed saw-shaped protrusions in the peregrine falcon. The connective tissue cores of the epithelium of the lingual apex showed thread-shaped protrusions in the common kestrel.

In the marginal region between the anterior and posterior parts of the tongue of the chicken, a close array of giant conical papillae was observed, arranged transversely in a row (Iwasaki and Kobayashi, 1986). On the tongue of the goose, giant conical papillae were located in a transverse row between the lingual body and the lingual radix (Iwasaki et al., 1997). At a point approximately $2 / 3$ of the length of the tongue in the white tailed eagle, between the body and the root of the tongue there were large conical papillae, the apices of which were pointed towards the posterior part of the tongue (Jackowiak and Godynicki, 2005). In the tongues of the peregrine falcon and common kestrel, the conical region between the lingual apex and lingual root was very wide area. There have been no reports regarding very wide conical area of the lingual dorsal surfaces in various ani- mals.

Jackowiak and Godynicki (2005) reported that the orifices of the anterior glands were situated on the lateral surfaces of the posterior part of the lingual body, whereas the posterior lingual glands open on the entire surface of the lingual root. In the mammals, some openings of the glandular ducts at the dorsal surfaces of the conical papillae of the lingual radix were observed in the tiger (Emura et al., 2004), fox (Jackowiak and Godynicki, 2004) and mole (Jackowiak, 2006). In the tongues of the peregrine falcon and common kestrel, the many openings of the lingual glands existed in the entire surfaces of the lingual body and lingual root. However, the openings of the lingual glands in the mammals are a small number than that of the white tailed eagle, peregrine falcon and common kestrel.

The white tailed eagle feeds mostly on fish and the peregrine falcon and common kestrel feeds on small animal. Furthermore, in the white tailed eagle the crest of the conical papillae found in the lingual body was sites aiding in the transfer of the swallowed food towards the oesophagus and at the same time preventing its regurgitation (Jackowiak and Godynicki, 2005). In the peregrine falcon and common kestrel, there were observed not only the crest but also the many conical papillae on the lingual body. Therefore, the differences in the structures of the tongues in the white tailed eagle and peregrine falcon and common kestrel may be by reason of the different feeding habits. In conclusion, the morphological characteristics of the tongues in the peregrine falcon and common kestrel were similar to each other. However, the morphological structure of the connective tissue cores of the lingual apex was different in each bird.

\section{Acknowledgements}

The authors would like to express their most sincere thanks to Dr. T. Okano of Wild Animal Rescue Center of Gifu University for their assistance in preparing the material for this study.

\section{References}

1) Emura S, Hayakawa D, Chen H and Shoumura S. Morphology of the lingual papillae in the tiger. Okajimas Folia Anat. Jpn. 2004; 81:39-44.

2) Emura S, Tamada A, Hayakawa D, Chen $H$ and Shoumura S. SEM study on the dorsal lingual surface of the northern fur seal, Callorhinus ursinus (in Japanese). Mammalian Science 2001; 41:187-194.

3) Homberger DG and Brush AH. Functional-morphological and biochemical correlations of the keratinized structures in the African Grey Parrot, Psittacus erithacus (Aves). Zoomorphology 1986; 106:103-114.

4) Iwasaki S, Asami T and Chiba A. Ultrastructural study of the keratinisation of the dorsal epithelium of the tongue Middendorff's 
bean goose, Anser fabalis middendorfii (Anseres, Antidae). Anat. Rec. 1997; 247:147-163.

5) Iwasaki S and Kobayashi K. Scanning and transmission electron microscopical studies on the lingual dorsal epithelium of chickens. Acta Anat. Nippon 1986; 61:83-96.

6) Jackowiak H. Scanning electron microscopy study of the lingual papillae in the European mole (Talpa europea, L., Talpidae). Anat. Histol. Embryol. 2006; 35:190-195.

7) Jackowiak H, Andrzejewski W and Godynicki S. Light and scanning electron microscopic study of the tongue in the cormorant Phalacrocorax carbo (Phalacrocoracidae, Aves). Zoological Sci- ence 2006; 23:161-167.

8) Jackowiak H and Godynicki S. The scanning electron microscopic study of lingual papillae in the silver fox (Vulpes vulpes fulva, Desmarest, 1820). Ann. Anat. 2004; 186:179-183.

9) Jackowiak H and Godynicki S. Light and scanning electron microscopic study of the tongue in the white tailed eagle (Haliaeetus albicilla, Accipitridae, Aves). Ann. Anat. 2005; 187:197-205.

10) Shindo J, Yoshimura K and Kobatashi K. Comparative morphological study on the stereo-structure of the lingual papillae and their connective tissue cores of the American beaver (Castor canadensis). Okajimas Folia Anat. Jpn. 2006; 82:127-138. 